\title{
Idiopathic scoliosis pathogenesis
}

\author{
M Dudin*, D Pinchuk \\ From 8th International Conference on Conservative Management of Spinal Deformities and SOSORT 2011 \\ Annual Meeting \\ Barcelona, Spain. 19-21 May 2011
}

Based on long-term investigations we have concluded that IS is a compensatory response of the vertebral complex and has several strictly sequential stages:

The first stage - pre-clinical. The usage of physiological kyphosis reserve (kyphosis is being transformed into lordosis).

The second stage - sub-clinical. Elimination of the "excess" length of osseous vertebra column owing to its torsion around relatively short medulla spinalis: frontal axis of shoulder (thoracic) girdle loses its parallelism relatively to the same axis of pelvis. "Operate" musclesrotators of caudal zone.

The third stage - clinical. Generated at the second stage stable shoulder (thoracic) girdle torsion is eliminated thanks to contra-lateral muscles-rotators in cranial zone and at the level where the process begins is left the most rotated vertebra that comes to be the top of the functional scoliosis. From that standpoint can be explained the well known fact of increased electro-activity of paravertebral muscles on the convex side of the scoliotic curve.

The fourth stage - vicious circle. Generated at the third stage functional frontal curve disturbs vertebra column biomechanics and creates all conditions for realization of Huter-Volkman's law. The order of the following actions is evident: asymmetric pressure brings to development of vertebrae bodies wedge-shape, which sequentially, increases the frontal curve, etc. During examination of such patients the physician becomes the witness of typical IS development - tragedy, where the stage is vertebral complex.

This opens up new horizons in treatment of scoliosis.

Published: 27 January 2012

Center of Rehabilitation for Children's Orthopedic Diseases, St.Petersburg, Russia

Ciomed Central

(c) 2012 Dudin and Pinchuk; licensee BioMed Central Ltd. This is an open access article distributed under the terms of the Creative Commons Attribution License (http://creativecommons.org/licenses/by/2.0), which permits unrestricted use, distribution, and reproduction in any medium, provided the original work is properly cited.
doi:10.1186/1748-7161-7-S1-P8

Cite this article as: Dudin and Pinchuk: Idiopathic scoliosis

pathogenesis. Scoliosis 2012 7(Suppl 1):P8.
Submit your next manuscript to BioMed Central and take full advantage of:

- Convenient online submission

- Thorough peer review

- No space constraints or color figure charges

- Immediate publication on acceptance

- Inclusion in PubMed, CAS, Scopus and Google Scholar

- Research which is freely available for redistribution 